\title{
Transforming the pharmaceutical workforce in the Eastern Mediterranean Region: a call for action
}

Banan Abdulrzaq Mukhalalati, ${ }^{1}$ Lina Bader, ${ }^{2}$ Asmaa Alhaqan ${ }^{3}$ and Ian Bates ${ }^{4}$

${ }^{1}$ Clinical Pharmacy and Practice Department, College of Pharmacy, Health Cluster, Qatar University, Doha, Qatar. ${ }^{2}$ International Pharmaceutical Federation, Netherlands. ${ }^{3}$ Department of Pharmacy Practice, School of Pharmacy, Kuwait University, Kuwait. ${ }^{4}$ School of Pharmacy, University College London, United Kingdom. (Correspondence to: Banan Mukhalalati: banan.m@qu.edu.qa).

\begin{abstract}
Planning and development of the pharmaceutical workforce is fundamental to achieving universal health coverage and the United Nations Sustainable Development Goals by 2030. The International Pharmaceutical Federation (FIP) has recognized the importance of constructing mechanisms for transforming the global workforce. FIP has launched a developmental road map in order to support and facilitate global, regional and national transformations of pharmaceutical education and the workforce. Literature on the pharmaceutical workforce in the WHO Eastern Mediterranean Region is limited but what there is reports persistent workforce challenges. This necessitates stronger engagement across all countries of the Region to develop workable and sustainable strategic plans for workforce and educational development by adopting and adapting approaches to national transformation needs and the FIP roadmap. Countries have an opportunity to engage with FIP in collaborative programmes to implement the FIP roadmap locally, and provide proof of concept and a leadership model for other WHO regions.

Keywords: pharmaceutical workforce, pharmacy education, World Health Organization, Eastern Mediterranean Region

Citation: Mukhalalati BA; Bader L; Alhaqan A; Bates I. Transforming the pharmaceutical workforce in the Eastern Mediterranean Region: a call for action. East Mediterr Health J. 2020;26(6):708-712. https://doi.org/10.26719/emhj.19.064

Received: 16/10/18; accepted: 26/02/19

Copyright (c) World Health Organization (WHO) 2020. Open Access. Some rights reserved. This work is available under the CC BY-NC-SA 3.o IGO license (https://creativecommons.org/licenses/by-nc-sa/3.o/igo).
\end{abstract}

\section{Global roadmap for the pharmaceutical workforce}

In September 2015, the United Nations (UN) General Assembly launched 17 Sustainable Development Goals (SDGs) that included targets relating to health and health care delivery. One of the SDGs describes achieving universal health coverage (UHC) by 2030, which is dependent on access to good quality health services including the safe and effective medicines and vaccines (1). In line with this, three of the six building blocks in the World Health Organization's (WHO) policies for health systems relate to the health workforce, health service delivery and access to essential medicines (2). Recognizing the importance of the health workforce in strengthening systems, the WHO launched the Global strategy on human resources for health: workforce 2030 in 2016. The strategy calls for quicker progress towards meeting both the SDGs and UHC by ensuring equitable access to a competent and capable health workforce (3). Considering the UN targets, WHO policy building blocks and the above-mentioned global strategy, it can be argued that the planning and development of the pharmaceutical workforce - collectively the health care experts in medicines - is fundamental in strengthening health systems, and for achieving the SDGs and UHC by 2030 (4).

The International Pharmaceutical Federation (FIP) is the global leadership body with an outreach to over four million pharmacists and pharmaceutical scientists around the world (5). FIP, through its formal relations with WHO and official partners, has recognized and communicated the importance of programmes to transform the pharmaceutical workforce, with a focus on global mechanisms for workforce development and education (5). FIP, through its relations with WHO, advocates for pharmacists' and pharmaceutical scientists' roles in the global health agenda.

FIP has continuously worked to expand the evidence on the education and workforce development through a series of global reports (6-8). These reports collectively represent a call for action with regard to transformation of the global pharmacy workforce (6). They include recommendations on integrating pharmacy workforce planning into broader national health workforce planning (7), emphasizing the importance of a needsbased approach in the development of a locally (nationally) relevant workforce (8). Regular reports on trends provide comprehensive up-to-date analyses of the global pharmacy workforce (9).

In 2016, FIP led the cocreation of a developmental roadmap to facilitate the global transformation of pharmaceutical education and the pharmaceutical workforce. The roadmap was developed in collaboration with national leadership bodies and was approved by consensus at the Global Conference on Pharmacy and Pharmaceutical Sciences Education held in Nanjing, China in 2016. The roadmap is composed of three main elements: a global vision for education and the workforce; a set of pharmaceutical workforce development goals; 
and a set of statements on pharmacy and pharmaceutical sciences education (the Nanjing Statements) (10).

The global vision for education and the workforce describes the future professional directions for workforce transformation and how education supports the evolution of practice and science. The thirteen pharmaceutical workforce development goals provide a systematic framework for clear measures and indicators to facilitate national workforce planning, implementation, and monitoring towards the achievement of the global vision. The goals are purposefully aligned with the SDGs and WHO strategies for human resources for health and health workforce transformation. The pharmaceutical workforce development goals are grouped into three clusters: "academy", with a focus on education providers primarily for initial education and training; "professional development" with a focus on pharmaceutical workforce development; and finally "systems", with a focus on systematic policy development, and governmental and leadership strategy (11).

The Nanjing Statements are primarily intended for providers of initial education and training as well as providers of continuing professional development and education. The document comprises 67 statements on education and training, grouped into eight clusters: shared global vision; professional skills mix; recruitment of students; foundation (early years) training and professional leadership; experiential education; resources and academic faculty; quality assurance; and continuing professional development (12).

\section{Evidence and implementation in the Eastern Mediterranean Region}

Published literature on the pharmaceutical workforce in the Eastern Mediterranea Region of WHO is limited compared with other health care professions $(13,14)$ and with other WHO regions that have substantially developed their health workforce intelligence strategies and processes $(15,16)$. The lack of critical literature on human resources and the health workforce is evident across the WHO Eastern Mediterranean Region in general (17), a situation that negatively affects workforce intelligence and monitoring in the health sector (18). However, it is worth noting that from the literature available one main challenge is the clear imbalance in the distribution and capacity of the pharmaceutical workforce. This suggests that better coordination and monitoring of the workforce both regionally and globally is urgently needed (19) while learning from experiences of other countries. For example, in New Zealand, Health Workforce has moved from predictive analytics using quantitative methods that estimate future numbers of health workers to the use of strategic foresight philosophy, which is focused on aggregated service models. These models consider the realities of the future of health care, advocate for contextual operational flexibility, and collect qualitative and behavioural information of workforce professionals and their professional registration data in order to improve health workforce distribution and provision (15).

The reports on workforce trends released regularly by FIP provide detailed analysis of capacity, production and gender trends across various WHO regions $(9,20)$. Both the 2015 and 2018 FIP reports on workforce intelligence indicated that the Eastern Mediterranean Region is showing a relative and absolute increase in capacity, as well as the largest proportional increase in pharmacist workforce and production compared with other WHO regions. Furthermore, the reports indicate that based on available data, Egypt and Jordan currently have some of the largest graduate production capacities in the world per capita (9). However, these observations, as pointed out in the 2018 report, are based on a limited number of countries of the Eastern Mediterranean Region providing data (six of the 21 Member States). This data gap necessitates a broader and stronger engagement across all countries of the Region, coordinated by FIP, in order to obtain the required data for future analysis of workforce intelligence and evidence-based recommendations. Furthermore, collective action by the pharmacy leaders in the Region is needed to strengthen workforce planning and development across all countries. Other research conducted in the Eastern Mediterranean Region highlighted an increasing number of pharmacy schools being established in some countries of the Region. This increase potentially has an impact on pharmacy practice and the supply of pharmacists to other countries through mobility and migration trends. Taken together, this may be indicative of a continued disconnect between the education, regulation and practice sectors that could be associated with lack of involvement of professional leadership bodies in workforce-related issues (9,21-24), including the significant, but largely unmeasured, impact of transnational professional migration.

The increased production of graduates and pharmacists in the Region, linked with inadequate data intelligence and workforce planning and career pathways, raises the issue of effective regulation and policy formation by policy-makers and professional leadership bodies. This is a critical issue and further raises concerns for the policy-makers in the Region (9). This situation requires urgent and concerted action across the Region, using a needs-based approach to develop a regional workforce development vision. We argue that based on evidence, implementation strategies and measures to monitor the workforce should ideally be mapped to the FIP global call for country case studies released in 2017 (9). This call aims to promote and align national workforce development projects with the systematic pharmaceutical workforce development goals in order to provide both a concerted and collaborative incentive for workforce transformation. By using the framework of the pharmaceutical workforce development goals and Nanjing Statements to identify national gaps and needs, countries of the Eastern Mediterranean Region will be able to identify gaps in policies and processes, and develop workable strategic plans for workforce development and educational policies based on adopting 
and adapting approaches to the national transformation needs. Furthermore, working collectively, stakeholders in the the Region could carry out a pilot regional case study in leadership, which could enable other WHO regions to establish similar proposals for the development of workforce planning and strategies based on identified need - a global cascade of concerted action and activities.

\section{Call for action: from country-level com- mitment to regional transformation}

The 2018 FIP report on workforce trends concluded that further focused work is needed at regional levels to initiate specific discussions around needs-based approaches and interregional commonalities for health workforce transformation. Therefore, stronger engagement and commitment to workforce development is needed by all countries of the Region to foster change at a regional level.

The Region can benefit from examining the experiences of other countries in strengthening the capacity and capability of the health workforce through local action based on loc al intelligence. These experiences include achieving a critical mass in the public health workforce by evaluating entry-level education and training, conducting structured work-based education and training models through traineeship schemes (such as foundation training), restructuring continuous professional development activities and facilitating specialization opportunities (often through further postgraduate training in management and leadership, for example) (16).

Collectively, individual national-level commitments would result in regional transformation in the Eastern Mediterranean Region. Such a regional-level transformation would offer a regional case study for other WHO regions. Coordinating a concerted regional effort requires better collaboration and participation of academic, practice, professional and governmental sectors across the Region in order to collectively engage with transformational mechanisms - the pharmaceutical workforce development goals and Nanjing Statements in order toidentify, address and monitor workforce trends, needs and progression. FIP has developed mechanisms to use and implement the Nanjing outcomes; for example, development of self-assessment tools from the Nanjing Statements and piloting a workforce transformation programme that facilitates national-level partnerships to transform the global workforce one country at a time.

Concerted regional action across the Region provides an opportunity for collaboration for the mutual benefit of the coutries. Such a regional commitment would build on the four strategic objectives of the Framework for action for health workforce development in the Eastern Mediterranean Region that was developed by the WHO Regional Office for the Eastern Mediterranean in 2018 to implement the global strategy on human resources for health (25). This would also advance and support the operationalization of the recently released Amman Commitment to action on primary health care reform for the Eastern Mediterranea Region (26). Furthermore, establishing a region-wide pharmaceutical workforce pilot case study provides a better pragmatic basis for workforce intelligence planning, educational reform, policy development and leadership advocacy by engaging all countries across the Region to contribute and share data for a systematic needs analysis. Transformative change at the regional level relies on the full commitment and engagement of each of the 22 countries of the Region. Only then can we make progress on the WHO global strategy in line with the regional framework for action for health workforce development.

The evidence obtained from a needs-based analysis of the pharmaceutical workforce and education policy can be used in the development of a focused and credible regionwide vision for workforce planning, and the creation of education and transformative policies for professional careers. These evidence-led policies would tackle the regional challenges, such as: long-term conditions requiring complex medicines, the medicines-related complexity of comorbidity, transformation to pharmacyled patient-focused services, improvement of pharmacy input into public health policy, and the development of regional leadership in professional practice for both young and experienced pharmaceutical professionals. There is no health care without a workforce and the time has come to pay more attention to this critical factor in the improvement of health for the countires of the Eastern Mediterranean Region.

Funding: Qatar University internal grant: QUSMCPH-2018-1.

Competing interests: None declared.

\section{Transformer le personnel pharmaceutique dans la Région de la Méditerranée orien- tale : un appel à l'action}

Banan Abdulrzaq Mukhalalati, ${ }^{1}$ Lina Bader, ${ }^{2}$ Asmaa Alhaqan ${ }^{3}$ et Ian Bates ${ }^{4}$

\section{Résumé}

La planification et le développement du personnel pharmaceutique sont essentiels à la réalisation de la couverture sanitaire universelle et des Objectifs de développement durable (ODD) des Nations Unies à l'horizon 2030. La Fédération internationale pharmaceutique (FIP) a reconnu l'importance de mettre en place des mécanismes de transformation du personnel à l'échelle mondiale. Elle a élaboré une feuille de route de développement afin d'appuyer et de faciliter les transformations de la formation et du personnel dans le secteur pharmaceutique aux niveaux mondial, régional et national. Dans la Région OMS de la Méditerranée orientale, la littérature sur le personnel pharmaceutique est limitée, 
mais les éléments dont on dispose font état de difficultés persistantes en ce qui concerne cette catégorie du personnel. Cela nécessite un engagement plus fort de tous les pays de la Région afin d'élaborer des plans stratégiques, réalisables et pérennes en matière de développement du personnel et de formation en adoptant et en adaptant des approches qui permettent de répondre aux besoins de transformation au niveau national et de mettre en œuvre la feuille de route de la FIP. Les pays ont l'occasion de s'engager avec la FIP dans le cadre de programmes collaboratifs afin de mettre en œuvre la feuille de route proposée par celle-ci au niveau local. C'est aussi la possibilité de proposer aux autres Régions OMS une validation de principe et un modèle d'encadrement.

$$
\text { تحوُّّل القوى العاملة الصيدلانية في إقليم شرق المتوسط: دعوة إلى العمل }
$$

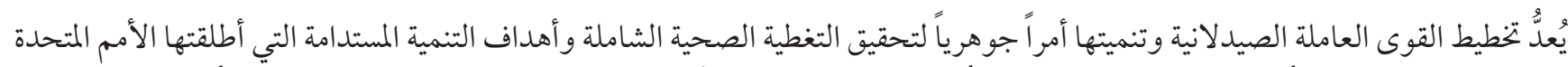

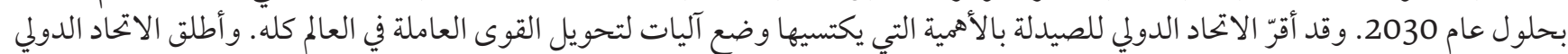

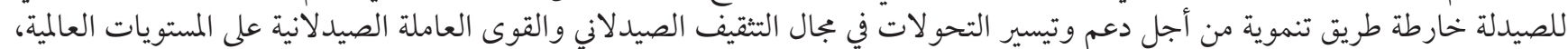

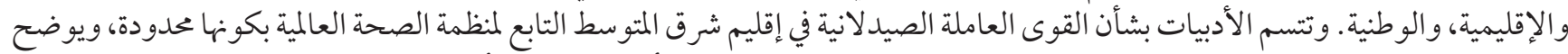

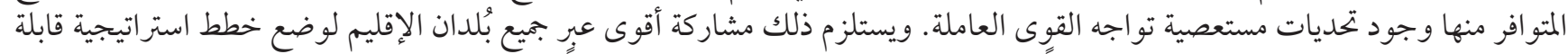

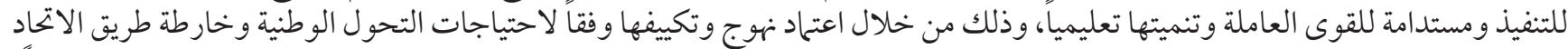

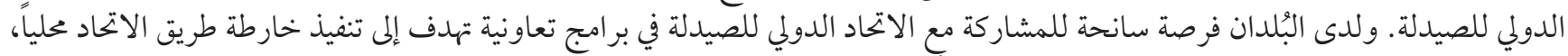

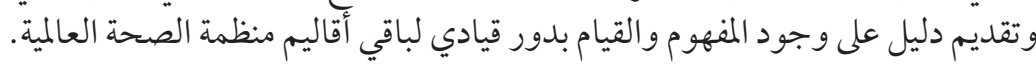

\section{References}

1. Tracking universal health coverage: 2017 global monitoring report. Geneva: World Health Organization; 2017.

2. Monitoring the building blocks of health systems: a handbook of indicators and their measurement strategies: Geneva: World Health Organization; 2010.

3. Global strategy on human resources for health: workforce 2030. Geneva: World Health Organization; 2016.

4. Bader L, Bates I, John C. From workforce intelligence to workforce development: advancing the Eastern Mediterranean pharmaceutical workforce for better health outcomes. East Mediterr Health J. 2018;24(9):899-904. https://doi.org/10.26719/2018.24.9.899

5. International Pharmaceutical Federation (FIP) (website) (https://www.fip.org/, accessed 31 August 2019).

6. Global pharmacy workforce and migration report: a call for action. The Hague: International Pharmaceutical Federation; 2006.

7. 2009 FIP global pharmacy workforce report. The Hague: International Pharmaceutical Federation; 2009.

8. 2012 FIP global pharmacy workforce report. The Hague: International Pharmaceutical Federation; 2012.

9. Global pharmacy workforce intelligence: trends report 2015. The Hague: International Pharmaceutical Federation; 2015.

10. Transforming pharmacy and pharmaceutical sciences education in the context of workforce development. The Hague: International Pharmaceutical Federation; 2017 (https://www.fip.org/www/streamfile.php?filename=fip/publications/FIPEd_Nanjing_ Report_2017_11.10.17.pdf, accessed 4 Novemebr 2019).

11. Pharmaceutical workforce development goals. The Hague: International Pharmaceutical Federation; 2016.

12. Research, development and evaluation strategies for pharmaceutical education and the workforce: a global report. The Hague: International Pharmaceutical Federation; 2017.

13. Desselle SP. Much needed attention devoted to pharmacy workforce issues. Res Social Adm Pharm. 2006;2(3):294-8. https://doi. org/10.1016/j.sapharm.2006.08.003

14. Hasan S, Sulieman H, Chapman C, Stewart K, Kong DCM. Community pharmacy in the United Arab Emirates: characteristics and workforce issues. Int J Pharm Pract. 2011;19(6):392-9. https://doi.org/10.1111/j.2042-7174.2011.00134.x

15. Rees GH. Addressing inadequate health workforce intelligence. Int Med J. 2015;45(9):887-9. https://doi.org/10.1111/imj.12847

16. Jenner D, Hill A, Greenacre J, Enock K. Developing the public health intelligence workforce in the UK. Public Health. 2010;124(5):248-52. doi: 10.1016/j.puhe.2010.03.007

17. El-Jardali F, Jamal D, Abdallah A, Kassak K. Human resources for health planning and management in the Eastern Mediterranean region: facts, gaps and forward thinking for research and policy. Hum Res Health. 2007;5(1):9. https://doi.org/10.1186/14784491-5-9

18. El-Jardali F, Makhoul J, Jamal D, Ranson MK, Kronfol NM, Tchaghchagian V. Eliciting policymakers' and stakeholders' opinions 
to help shape health system research priorities in the Middle East and North Africa region. Health Policy Plan. 2009;25(1):15-27. https://doi.org/10.1093/heapol/czpo5

19. Hawthorne N, Anderson C. The global pharmacy workforce: a systematic review of the literature. Human Res Health. 2009;7(1):48. https://doi.org/10.1186/1478-4491-7-48

20. Pharmacy workforce intelligence: global treands report 2018. The Hague: International Pharmaceutical Federation; 2018.

21. Bajis D, Moles R, Chaar B. Stakeholders' perspectives on quality assurance in the Eastern Mediterranean Region. Am J Pharm Educ. 2018;82(10):6482. https://doi.org/10.5688/ajpe6482

22. Bader LR, McGrath S, Rouse MJ, Anderson C. A conceptual framework toward identifying and analyzing challenges to the advancement of pharmacy. Res Social Adm Pharm. 2017;13(2):321-31. https://doi.org/10.1016/j.sapharm.2016.03.001

23. Kheir N, Zaidan M, Younes H, El Hajj M, Wilbur K, Jewesson PJ. Pharmacy education and practice in 13 Middle Eastern countries. Am J Pharm Educ. 2008;72(6):133. https://doi.org/10.5688/aj7206133

24. Kheir N, Fahey M. Pharmacy practice in Qatar: challenges and opportunities. South Med Rev. 2011;4(2):45-9. https://doi. org/10.5655/smr.v4i2.1007

25. Framework for action for health workforce development in the Eastern Mediterranean Region 2017-2030. Cairo: World Health Organization Regional Office for the Eastern Mediterranean; 2018.

26. The Amman Commitment to Action on Primary Health Care. International Pharmaceutical Federation; 2019 (https://amman2019.congress.pharmacy/amman-jordan/, accessed 31 August 2019). 